6-2005

\title{
Standards Deviation: How Schools Misunderstand Education Policy
}

James P. Spillane

Follow this and additional works at: https://repository.upenn.edu/cpre_policybriefs

Part of the Curriculum and Instruction Commons, Educational Administration and Supervision Commons, Educational Assessment, Evaluation, and Research Commons, Educational Leadership Commons, Education Policy Commons, Science and Mathematics Education Commons, and the Teacher Education and Professional Development Commons

\section{Recommended Citation}

Spillane, James P.. (2005). Standards Deviation: How Schools Misunderstand Education Policy. CPRE Policy Briefs.

Retrieved from https://repository.upenn.edu/cpre_policybriefs/31

View on the CPRE website.

This paper is posted at ScholarlyCommons. https://repository.upenn.edu/cpre_policybriefs/31

For more information, please contact repository@pobox.upenn.edu. 


\title{
Standards Deviation: How Schools Misunderstand Education Policy
}

\begin{abstract}
Instructional policy reforms that focus on standards and assessments have gained popularity in the last two decades. State governments, which had previously left most instructional matters to local governance, set challenging learning standards and developed related assessments and curricular frameworks. Despite their popularity and persistence, standards-based reforms face the challenge of successful local implementation. Occupying an intermediary position between the statehouse and the schoolhouse, the local school district has significant potential to influence standards implementation. It is important to consider the consequences for classroom instruction of what districts do in response to standards. While states may set standards and provide incentives for implementing them, district policies often determine how teachers comprehend the standards.
\end{abstract}

This issue of CPRE Policy Briefs summarizes the findings of a recent book, Standards Deviation: How Schools Misunderstand Education Policy (Spillane, 2004), that examines state and local government relations as the standards move from the statehouse to the district policymakers and teachers who attempt to make sense of them. It takes a case study approach, focusing on a single state, Michigan, and strategically sampled school districts. The study is based on empirical data from a four-year examination of approaches to the use of standards in nine Michigan districts between 1992 and 1996. The sample included three midsize city districts, two suburban districts, and four rural districts. Mixed methods, including semistructured interviews, questionnaires, and observations, were used to gather data at state, district, and school levels on implementation of math and science standards.

This overview of the study's findings first frames the subject of standards-based reform, and then moves to a discussion of the Michigan math and science standards. Variation in the progress of standards among districts is explored next, followed by a cognitive explanation for the variation and a discussion of districts' resources. Next, variation in teachers' beliefs about and implementation of the standards is analyzed. The overview closes with implications of the study for policy outcomes, analysis, and design.

\section{Disciplines}

Curriculum and Instruction | Educational Administration and Supervision | Educational Assessment, Evaluation, and Research | Educational Leadership | Education Policy | Science and Mathematics Education | Teacher Education and Professional Development

\section{Comments}

View on the CPRE website. 


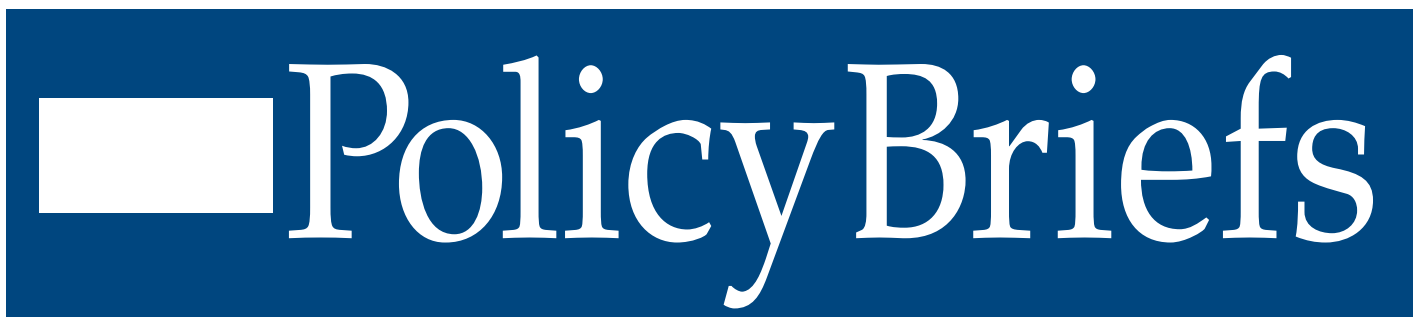

Reporting on Issues and Research in Education Policy and Finance
June 2005 RB-43

Graduate School of Education

University of

Pennsylvania Misunderstand Education Policy

\section{By Jim Spillane}

Instructional policy reforms that focus on standards and assessments have gained popularity in the last two decades. State governments, which had previously left most instructional matters to local governance, set challenging learning standards and developed related assessments and curricular frameworks. Despite their popularity and persistence, standards-based reforms face the challenge of successful local implementation. Occupying an intermediary position between the statehouse and the schoolhouse, the local school district has significant potential to influence standards implementation. It is important to consider the consequences for classroom instruction of what districts do in response to standards. While states may set standards and provide incentives for implementing them, district policies often determine how teachers comprehend the standards.

This issue of CPRE Policy Briefs summarizes the findings of a recent book, Standards Deviation: How Schools Misunderstand Education Policy (Spillane, 2004), that examines state and local government relations as the standards move from the statehouse to the district policymakers and teachers who attempt to make sense of them. It takes a case study approach, focusing on a single state, Michigan, and strategically sampled school districts. The study is based on empirical data from a four-year examination of approaches to the use of standards in nine Michigan districts between 1992 and 1996. The sample included three midsize city districts, two suburban districts, and four rural districts. Mixed methods, including semistructured interviews, questionnaires, and observations, were used to gather data at state, district, and school levels on imple- mentation of math and science standards.

This overview of the study's findings first frames the subject of standards-based reform, and then moves to a discussion of the Michigan math and science standards. Variation in the progress of standards among districts is explored next, followed by a cognitive explanation for the variation and a discussion of districts' resources. Next, variation in teachers' beliefs about and implementation of the standards is analyzed. The overview closes with implications of the study for policy outcomes, analysis, and design.

\section{Framing Standards-Based Reform}

Local education officials typically construct responses to policies such as curriculum standards on the basis of particular understandings. Conventional accounts (see Firestone, 1989) assume that local officials understand the policy message as intended and choose rationally between following or ignoring it. However, this assumption is problematic if we take a cognitive perspective. Under rubrics that include "interpretation," "cognition," "learning," "sense making," and "reading," scholars holding this perspective argue that the ideas that implementing agents come to understand or interpret from policy are an integral, and largely unexplored, component of the implementation process. These scholars investigate how people make sense of new ideas and how this process influences implementation. Some work concentrates on implementing agents' prior knowledge (EEPA, 1990; Weiss \& Cohen, 1993) and the analogies that implementing agents draw between new ideas and their existing understandings (Spillane, 2000). Other work concentrates on how

\section{Consortium for Policy Research in Education}

University of Pennsylvania

Harvard University

Stanford University

University of Michigan

University of Wisconsin-Madison 


\section{Policy Briefs}

aspects of the social situation-including organizational and community history (Lin, 2000; Yanow, 1996), organizational segmentation and professional expertise (Spillane, 1998), professional discourse (Hill, 1999), and formal and informal networks (Coburn, 2001)influence implementing agents' sense making. From this perspective, local officials understand the message in different ways, not necessarily those that state policymakers intend. They construct their action on the basis of their previous understandings and ideas about local behavior. The sense-making process is fraught with opportunities for both misunderstandings and fruitful reconstruction of existing knowledge. As district officials interpret state policy and pass their understandings to school leaders and teachers, the process resembles the "telephone game": The person at the start of a line tells a story to the next, and so on, until a different story emerges at the end.

Historically, fundamental changes in classrooms have largely been orchestrated at the local level. Standards-based reform represents an ambitious shift towards the more active engagement of state governments in instructional policymaking and towards more intellectually rigorous K-12 instruction. Approaches based on standards involve four core elements: curricular frameworks, alignment of state policies, teacher development, and accountability mechanisms. State policymakers have welcomed these strategies and indicators of the movement's progress are impressive if not uniform (see Firestone, Fitz, \& Broadfoot, 1999). Such reform is not easy. Decades of research suggest that classroom practice is resistant to reform initiatives, particularly because local officials have considerable discretion in implementation.

Reform of learning standards entails complex intergovernmental relations. The standards movement envisions a more active role for states, putting individual schools in direct contact with state instructional guidance. While the local school district has not figured prominently in these reform policies, history suggests that the actions of district administrators are crucial to successful policy implementation. District curricular policies can amplify or drown out the salience of state-initiated reforms for teachers (Spillane, 1996).
The Consortium for Policy Research in Education (CPRE) is funded by the Institute of Education Sciences, United States Department of Education under Grant No. R308A960003. Opinions expressed in this Brief are those of the authors and do not necessarily reflect the views of the Institute of Education Sciences; the United States Department of Education; Research for Action; CPRE; or its institutional members.

Further, in most states, districts are the most important source of revenue supporting state policy. Districts still enjoy much autonomy, and states generally rely on districts to implement state policy, lacking the financial and human resources to do so themselves. Because districts are both implementers of state policy and policymaking entities themselves, we can expect that state standards initiatives might stimulate district-level instructional policymaking.

\section{State Standards: Content and Context in Michigan}

Standards received considerable attention from school reformers and policymakers in Michigan, a state with a tradition of local education control. By the late 1980s, state education officials and educators were revising state math and science policies to emphasize new instructional ideas. Policymakers revised the state's assessment policy, the Michigan Educational Assessment Program (MEAP), and worked towards a major shift of Michigan's Essential Goals and Objectives for reading, math, and science from a focus on minimum skills to a focus on intellectually challenging content.

\section{Content}

The Michigan Department of Education (MDE) was ill equipped to revise the goals and objectives for math and science. MDE relied on university academics, local educators, and the state math and science teachers associations to assist in this work. Drawing on these sources and on National Council of Teachers of Mathematics (NCTM) standards, MDE revised the state math standards. The department urged substantial shifts in K-12 math content and pedagogy towards balancing procedural and principled mathematical knowledge. Procedural knowledge centers on computational procedures and involves memorizing and following predetermined steps to compute answers, while principled knowledge focuses on the mathematical 
ideas and concepts that undergird mathematical procedures. Although procedural knowledge has long dominated the K-12 curriculum (see Romberg, 1983), reformers want principled mathematical knowledge to receive more attention in schoolwork (Greeno, Riley, \& Gelman, 1984; Lampert, 1986; Leinhardt \& Smith, 1985). MDE further urged that curricular content focused on problem solving, math reasoning, multiple representations of ideas, and connecting math to daily life would strengthen students' knowledge of mathematics. The state also sought changes in math pedagogy to encourage students to construct new knowledge on the basis of prior knowledge and new experiences. Although Michigan's math standards were compatible with national standards, they were not developed in depth or detail.

Relying heavily on the recommendations for students' scientific literacy in Science for All Americans (AAAS, 1989), MDE officials, the state science teachers association, and local educators revised the state's science standards. The new standards stressed transforming the science curriculum from a mix of isolated facts to understanding fundamental scientific concepts with rich explanatory power. Reformers wanted students to use scientific knowledge to develop hypotheses, justify their findings, and draw conclusions. They argued further that students should understand science in real-world circumstances. Also promoted were changes in pedagogy to encourage construction of new knowledge. Unlike the math standards, the science standards elaborated on core ideas through essays explaining key concepts and their instructional use.

\section{Context}

The challenges facing state policymakers in implementing the new standards were immense. Most teachers lacked the training in math and science needed to carry out the changes. Moreover, the new ideas about classroom practice, especially in mathematics, were not well developed. Other key challenges appeared in the broader policy context. Because MDE was understaffed and underresourced, the agency relied on persuasion to get districts and schools to heed the standards. MDE gave presentations about the standards to districts and organizations statewide. However, the magnitude of Michi- gan's education system dwarfed MDE capacity; the department had only one math and two science coordinators. These coordinators had meager budgets to support state policy implementation. Their presentations could only provide broad overviews of the standards insufficient to promote local implementation.

Unable to reach many educators directly, MDE tried to reach them indirectly through policy instruments. MDE worked to align standards with the mandatory MEAP, revising both the MEAP math and science assessments. However, without funds or political support for developing open-ended and performance items, the revised math assessment was almost entirely multiple choice, focusing on procedural knowledge. Thus it failed to represent the depth of the changes envisioned in state standards. Circumstances differed for the science assessment, revised some years later. It included performance and constructed response questions more aligned with standards. Further legislative changes in the early 1990s aimed to give the standards more influence. For instance, the state mandated core curriculum for all districts and new school compliance mechanisms tying state accreditation to MEAP scores.

Michigan's volatile political context also hindered standards-based reform. Conflict during the mid-1990s between the governor, who wanted to increase the influence of MEAP, and the State Board of Education, which wanted to limit it, left MDE caught in the middle. Critical of the department, the governor reduced MDE staffing and responsibility. Such political tensions contributed to numerous state policy changes that brought new procedural requirements that districts had to meet. The changes distracted districts from standards implementation, and it was unlikely that the standards would have much impact on practice without the support of the districts themselves.

\section{Gauging Progress}

Gauging policy progress was difficult in this case; it was hard to find reasonable criteria for monitoring standards use in districts and schools, given the vague and shifting policy goals. However, it was clear that the new Michigan math and science standards stressed balancing the prevailing procedural 
knowledge with more principled knowledge. For standards to be successfully implemented locally, at least two dimensions of classroom instruction would have to change to reflect the new balance: students' academic tasks and their discourse around those tasks (that is, the ways they communicate about them, for example by defending solutions to a math problem). Teacher-student interaction would also have to change to give students opportunities to build principled knowledge through evaluating their ideas. Having a way to gauge progress towards these changes in knowledge was important because teachers could-and did-adopt new materials and activities without changing the intellectual rigor of instruction. Districts' and teachers' progress, measured by these changes, proved uneven, as the following examination of responses to standards-based reform in Michigan demonstrates.

\section{District Responses: Interactive Policymaking}

\section{Districts}

The nine Michigan districts studied made sense of state standards initiatives as makers of local policies, interacting with state policymakers to interpret the new policy in terms of local conditions. Instructional policymaking was a relatively recent pursuit for most districts. Most had responded to increased state policymaking in the 1980s by developing their own instructional policies. Professional educators-district and school administrators, curriculum specialists, and teachers-rather than elected officials or community elites were the chief instructional policymakers in these districts. In larger districts, science or mathematics specialists took responsibility for instructional policymaking. In smaller districts, classroom teachers often took leadership roles.

A variety of sources informed districts' instructional policymaking. These sources included state policy, foundations, and other states' curriculum documents. Professional associations and networks connecting state and federal officials were important sources. NCTM standards were particularly influential. Moreover, district officials combined external sources such as universities and foundations with sources inside MDE. District and state policymakers relied on many of the same sources for ideas about standards. By participating in state instructional policymaking, some district officials gained knowledge of standards policy that gave their districts a competitive edge. In addition to the variety of sources and messages, the segmentation of responsibility for instructional policymaking within the districts added a further complication, especially in larger districts. Segmentation resulted in an array of parallel but not aligned or uniform policies. Administrators and teachers were often challenged with figuring out how to integrate this mix of policies.

Districts deployed various policy strategies to support standards implementation. Most districts revised their math and science curriculum guides and used math and science textbooks linked to the guides. Professional development was an important strategy in all the districts, although it was mobilized differently. Most districts used external consultants to present new instructional approaches. Many topics were presented but were rarely integrated, resulting in a fragmented curriculum for teacher development. It was left to teachers to put the different pieces together in their classroom practice. A few districts used an alternative strategy. Believing that teachers themselves should be key agents in their learning, they accorded a central role to teacher leaders and to dialogue about classroom implementation of standards.

\section{The State}

While district officials had considerable autonomy, they endeavored to ensure that district policies supported the state standards. Yet the ways they made sense of the standards are more interesting than their dedication to ensuring implementation. The sense that district policymakers made of state standards was influenced by the variety of sources of their understanding and by their districts' histories in instructional policymaking. State standards were especially influential in the three districts that had previously had no mathematics and science policies. District officials saw state sanctions as key motivators of their response to instructional polices, singling out the importance of MEAP performance for accreditation as crucial. 
MEAP empowered and motivated district policymakers to leverage change.

\section{Progress of Standards}

The progress of district policies in supporting state standards varied, but in one aspect of reform, state policy had a powerful and uniform effect on district policymaking. Michigan curricular policy specified K-12 math and science topics and their sequencing; support for bringing curriculum in line with these specifications was consistent across the study districts. However, district policies offered weak support for those aspects of reform that sought fundamental changes in what counted as mathematical and scientific knowledge. In only a third of districts did policy support go beyond topic coverage and sequencing to support for more fundamental changes in curricular content that would work to balance principled and procedural knowledge. Instructional policies in most districts drowned out the complex epistemological aspects of the state reform message, resulting in greatly varying support for the measures.

\section{District Responses: Making Policy, Making Sense}

An important explanation for the observed variation in implementation was the variation in how district policymakers understood the ideas pressed by the standards. Many local policymakers understood the standards as primarily entailing changes in content coverage; few understood them as entailing the intended changes in conceptual approach to mathematics and science. It was difficult to achieve a shift from the former, longstanding view of standards, which seemed more practical to many district administrators.

\section{Making Sense of Policy}

Having noticed an event, interpreters relate it to their prior experiences and knowledge (Mandler, 1984). The sense made of new policy thus depends on existing understandings. Moreover, most interpreters are drawn to the familiar and tend to ignore other ideas. Accordingly, Michigan reform ideas that were more familiar got local policymakers' attention. For example, "hands-on" science, a familiar idea included in state standards, fig- ured more prominently in district policymakers' understanding than less familiar ideas, such as "constructivist learning."

The development of new understanding requires the overhaul of existing mental scripts. Regrettably for those seeking major changes in people's knowledge, we tend to hang on to existing scripts, and new ideas are understood as familiar ones because we attend to superficial similarities between new and existing knowledge instead of deeper structural parallels. District policymakers often perceived reform ideas as more familiar than they were. For instance, some understood the standards' notion of problem solving as identical to conventional story problems or as similar to the familiar idea of linking math to real life. They missed the new concept of making math problematic so that students would explore principles further. Most district officials also focused on the superficial features of the standards' ideas. They focused on changing student grouping or making math and science relevant to students' lives. But the architects of the state standards envisioned more profound mathematical and scientific activity-questioning, probing for solutions, and defending ideas.

\section{Local Understandings}

In the three districts (two suburban and one rural) where policies provided strong support for standards (i.e., advocating the fundamental changes in knowledge urged by the state), more policymakers developed deeper understandings of reform ideas than in the six districts providing low support (i.e., advocating perfunctory curricular changes). With respect to math standards, almost 95\% of policymakers in the low-support districts expressed surface-level understandings, while in the high-support districts, understandings were evenly split between superficial and deeper ones. The situation was similar with respect to science standards. This evidence demonstrates significant, if not necessarily causal, relations between policymakers' understandings and district support. Overall, there was only modest change in existing understandings. 
Why did some policymakers develop deeper knowledge? Cognitive theory suggests that resources for sense making can influence depth of understanding.

\section{District Responses: Resources for Sense Making}

For district policymakers in Michigan, developing deeper understandings of the ideas pressed by state standards was arduous, resource-intensive work. Human, social, and material resources were pivotal factors in policymakers' sense making.

\section{Human Resources}

District policymakers' knowledge, expertise, and skill helped them focus on more conceptual features of the reform ideas. Policymakers expanded their subject-matter and pedagogical expertise through connections outside their districts, ongoing work with colleagues, and teaching. In high-support districts, policymakers were disposed to learning about math and science instruction. They understood that to change instruction, they would have to acquire knowledge. While individual expertise was necessary, it was not sufficient. Critical was whether district policymakers recognized the importance of their human resources and mobilized them. In high-support districts, leadership invested in a handful of expert individuals and mobilized them to develop a knowledgeable collective. The situation was different in low-support districts. There, administrators failed to tap teacher expertise to make sense of standards.

\section{Social Resources}

In Michigan, social resources for sense making differed between high- and low-support districts. Two forms of resources-social networks and norms of trust-were more prevalent in high-support districts. Here, strong professional networks developed policymakers' individual resources. High-support districts accessed a variety of professional networks. Policymakers participated in and forged ties with numerous external organizations working to reform math or science education. Social networks were especially important in smaller districts with less finances and staffing. One district networked with a university, building expertise for fun- damental change in the local math curriculum without burdening the district. Strong, long-term ties between district policymakers and external experts helped districts tailor knowledge development to local attempts to interpret standards. Districts making the greatest strides in revising math and science policies also established greater trust among administrators and teachers. Trust created an environment in which local educators were comfortable discussing their interpretations of and reservations about standards; such conversations were essential for developing deeper insights. In districts with low administrator-teacher trust, however, collaboration around standards faced major hurdles.

\section{Staffing, Time, and Material Resources}

For district policymakers who developed deep understanding of state standards, sense making took considerable time and material resources. Time and staffing shortages were particularly salient in smaller districts, where limited staff meant less time investment in instructional reform. In general, policymakers had an assortment of disconnected responsibilities that reduced their time for instructional concerns. How policymakers used their available time was critical. In highsupport districts, they devoted much time, sometimes years, to figuring out standards. But in low-support districts, time was typically used to address short-term procedural concerns, such as creating mandated curriculum documents. Further, the extent to which material resources, such as textbooks and curriculum guides, contributed to policymakers' sense of standards varied widely among districts. Only in the high-support districts were new materials used to focus conversations about the implications of standards for instruction.

\section{State Resources}

State resource strategies helped districts take standards seriously but also contributed to surface-level understandings. Lacking resources for oversight, MDE had to rely on proxies for implementation. The agency required each district to file its core curriculum and publish an annual report. In four districts, these state requirements focused local attention and resource use on procedural compliance. Moreover, districts could be in 
compliance but still lack support for fundamental changes in knowledge. Curricular materials could be on file that teachers did not use or know how to use. Given the limitations of state resources, variation in district resources for sense making and support of standards was consequential for what teachers did in math and science lessons.

\section{Teachers' Beliefs and Standards}

\section{Sources of Advice}

Although teachers in the Michigan study received guidance about math and science standards from various sources, the most important were district curriculum policies. Teachers reported that district science policies influenced their instructional approach and materials. One district provided prepared materials that enabled teachers lacking confidence in science to acquire expertise. Teachers also reported that district efforts to reform math education through professional development, curriculum frameworks, and district leaders' communication were important instructional influences. Some state policy instruments were also influential. Almost all teachers also reported familiarity with the state math and science standards and with MEAP. Professional sources such as NCTM standards had less influence.

\section{Teachers' Beliefs About Practice}

The extent to which teachers' beliefs about instruction were consistent with the ideas pressed by the standards constituted a measure of the standards' success. A survey of teachers' beliefs about mathematics reform suggests that teachers' thinking was indeed consistent with some of the reform concepts. For example, nine in ten teachers thought it very important for students to understand mathematical principles and the real-world use of math. Moreover, many teachers surveyed reported teaching math and science in ways that approximated aspects of the standards. Some standards-oriented math practices were implemented much more widely than others. For example, over $60 \%$ of teachers reported that they had students explain their reasoning in most lessons. Yet problem solving, paramount in the standards, was used by only $55 \%$, while $40 \%$ never or almost never used it. Interviews suggested that most teachers using problem solving did not implement standards-oriented practices, such as using problems without obvious solutions. In science instruction, evidence of practice consistent with standards also appeared. For example, over $60 \%$ of teachers had students explain their reasoning in most lessons. Grouping arrangements represented a blend of conventional and standards-oriented practices. The standards encouraged using groupwork for discussion of ideas. Most teachers reported using groups in at least some lessons. Conventional teacher-led arrangements predominated, especially in math.

Overall, standards-oriented practice appears to have progressed unevenly in the classrooms surveyed. Success was evident in the reporting of ideas and instruction consistent with standards. However, this evidence must be interpreted cautiously. It is difficult to tell from the survey whether the classroom content mostly addressed principled or procedural knowledge, a key question for successful implementation.

\section{The Interaction of Advice and Beliefs}

\section{About Practice}

Because district policies were teachers' most important source of instructional guidance, one might expect teachers in high-support districts to teach in ways more consistent with math and science standards than those in low-support schools. Regression analyses correlating district policy and teacher reports of standards-oriented instruction showed that degree of support and standards-oriented instruction were indeed related. Teacher familiarity with the district curriculum guide was a significant predictor of standards-oriented math instruction only for the three districts with high support for math standards. The situation was similar for science. District support did matter for classroom implementation of standards.

Districts were not the whole story. In the three high-support districts for math, teacher familiarity with the math MEAP was also a significant predictor of standards-oriented instruction, as was teachers' reliance on other teachers or math specialists. In some instances, school or department-level initiatives such as teacher collaboration amplified district messages. For the six low-support districts, teacher familiarity with NCTM 
standards was a significant predictor of standards-oriented math instruction. Thus districts exerted differing influences on teachers, mediated by numerous factors. Some district interpretations seemed to drown out ideas advanced by state standards, unwittingly interfering with classroom implementation as measured by teacher questionnaire data.

\section{Teachers' Practices and Standards}

\section{Uneven Progress}

Was what teachers actually did to carry out standards consistent with policymakers' intentions? From 25 Michigan classrooms observed, there was considerable evidence of similar mathematics practices in support of state standards. Teachers in these classrooms emphasized problem solving, linking math to the real world, using multiple representations, and combining group and individual instruction. However, these surface similarities cloaked significant differences visible in the typical lessons of two elementary teachers. Both used problem solving and took standards seriously. Yet their understandings and enactments of problem solving contrasted sharply. One teacher set up a problem-solving task designed to elicit principled knowledge about the concepts underlying fractions and orchestrated discussion that encouraged students to assess their ideas. In contrast, the other teacher's task conveyed procedural knowledge about division without investigation of underlying concepts or opportunities for student reasoning. Instruction in most classrooms resembled that of the teacher emphasizing procedural knowledge. In only four classrooms, mostly in one high-support district, did student activities balance principled and procedural knowledge, while procedural knowledge predominated in eleven classrooms, many in low-support districts. The remaining classrooms fell between these levels of implementation.

The four teachers whose instruction most closely matched the standards designed math tasks to help students grasp mathematical concepts. Problems were set up so that students could not solve them merely by applying a procedure. Discourse patterns in these classrooms foregrounded principled knowledge. Teachers constantly pressed students to communicate and reason. The eleven teachers most distant from the standards designed math tasks chiefly to help students develop procedural skills, even when the tasks involved problem solving. The tasks were often exclusively concerned with computing right answers using predetermined formulas. Discourse patterns in these eleven classrooms focused on using procedures to reach correct answers, whether students worked alone or in groups; further discussion was rare. In the remaining classrooms, teachers oriented tasks towards principled knowledge, but the conversations around the tasks focused chiefly on procedural knowledge. Clearly, some teachers practiced in ways consistent with math standards, while others did not. How can this difference be explained?

\section{Teachers' Opportunities for Sense Making}

Variation in attention to standards or in willingness to implement them does not account for the uneven progress of math standards among classrooms studied. All teachers gave extraordinary attention to standards and were dedicated to teaching them. Neither do differences in prior practice or prior knowledge explain the uneven progress. A more satisfactory explanation comes from differences in the ways teachers made sense of the standards. Like district policymakers, most teachers did not understand the fundamental nature and extent of the changes they would have to make. Those who successfully made deeper changes made sense of the standards in specific ways.

Crucially, teachers making deeper changes described their efforts to interpret standards as social. For them, sustained conversations with colleagues were central to grasping the standards. These discussions allowed teachers to exchange ideas and confirm their emerging understandings of problem solving and discourse. Moreover, teachers whose practice matched standards had opportunities for public discussions of their own classroom practice. Shared observations of practice and open sharing of classroom activities facilitated deeper understanding of the math standards. The teachers making more superficial changes described their 
sense making as more solitary. Only three of these teachers engaged in any sustained conversations about math instruction. They rarely mentioned public sharing of their own instruction. They had few opportunities to test their understandings of reform ideas. Also important for the sense making of teachers who made deeper changes was access to sense-making opportunities directly related to standards. For most, the district provided these focused opportunities. Professional development connected to the key ideas of standards was provided. In contrast, the teachers making more superficial changes had opportunities to learn that were less related to instruction around standards.

Most of the teachers with practices approximating the math standards worked for one district that provided superior social resources and opportunities to learn. The district encouraged communication among teachers about standards and their implementation, and school administrators viewed conversations among teachers as beneficial. The teachers with less matching practices were less fortunate. They worked in districts where the social resources were scarce or never mobilized. The district with the most standards-oriented teachers differed from the other two high-support districts in creating opportunities for teachers' sense making that were social, coherent, and grounded in ongoing conversations about practice.

\section{Implications}

What mattered most for standards implementation in Michigan, then, was what district leaders and teachers came to understand from standards. Many district policymakers and teachers constructed messages about reformed practice that misconstrued the intentions of state policymakers in important ways. Between the statehouse and the schoolhouse, many understandings intervened, increasing the likelihood of misunderstanding, as in a complicated version of the telephone game, with multiple "party lines" relaying ideas to teachers. For example, the state's assessment system, the standards documents, related national standards, and other instruments influenced districts. These constituted different and not always consistent representations of ideas about reforming math and science education; it was difficult for districts to determine what "the policy" to be implemented was. Because districts were not of one mind about revising math and science education, teachers received differing advice about implementation.

Research in other states at both the district and classroom levels corroborates this account. Studies in states from Maine to California suggest that district policymakers, teachers, and school administrators heed state policies and work hard to implement them, but still local implementations fall far short of state policymakers' goals (EEPA, 1990; Finnigan \& Gross, 2001; Firestone, Fitz, \& Broadfoot, 1999; Hill, 2001; Koertz, Mitchell, Barron, \& Keith, 1996; Lane, Stone, Parke, Hansen, \& Cerrillo, 2000; McDonnell and Choisser, 1997; Stecher, Barron, Chun, \& Ross, 2000). Local agents' understanding of the ideas pressed by standards was a key factor in accounting for these patterns. For example, a study of the implementation of standards-based mathematics reforms in four Colorado school districts with standards in place for several years found "great variability" in local educators' understandings, ranging from interpreting the state reform as a curricular checklist to understanding it as involving fundamental change in classroom practice (Haug, 1999, p. 256). Similarly, a study of California teachers' responses to language arts reforms shows that teachers' sense making was a critical factor in accounting for their implementation of the reforms (Coburn, 2001).

\section{Policy Outcomes}

The Michigan study suggests that while the state math and science standards were not a great success, neither were they a total failure. If its intention was to fundamentally transform what and how students learn, then Michigan's reform of learning standards was not successful. While problem solving and real-world links became more prevalent, one of the central reform objectives, changing what counts as knowledge in order to improve student performance, was achieved by only a handful of teachers in one district. Yet these teachers demonstrate that under the right conditions, state policy can enable teachers to make fundamental changes in practice. The study shows that a basis exists for broader and more sustained success in 
altering classroom practice, if more time, resources, and local policymaker understanding come together. Furthermore, there was policy success in Michigan from the local if not the state perspective. Standards could meet local needs-for example providing some districts with math and science curricula for the first time-although falling short of state objectives.

\section{Policy Analysis}

The findings of the Michigan standards study suggest issues for future investigation. For example, relations between local agents' existing values and their sense making influenced implementation, but they are not yet well understood. Further, it became clear that sense making took time; we know relatively little about sense-making practice as it unfolds in interactions such as curriculum committees and professional development sessions. Exploring the activity structures that define sense making would enrich our understanding of policy implementation.

\section{Policy Design}

The more fundamental the changes sought by a policy, the greater the extent to which existing scripts must be restructured, and the greater the design challenges. One challenge emerging from the Michigan study involves designing representations that enable locals to understand reform ideas. A dominant representation used by state policymakers is a series of brief objectives; other less common ones are extended essays that explain and justify reforms. State policymakers should consider whether these more elaborate representations would facilitate local sense making. Policy designers might anticipate possible misconceptions of their reform ideas and develop representations that communicate better the underlying rather than the surface features of the ideas.

\section{Prospective}

If the Michigan study is roughly right, the success of recent state standards reform and of other reform policies such as the federal No Child Left Behind legislation will depend in considerable measure on school districts. Because state and federal agencies have limited capacity for reaching far-flung classrooms, enlisting district policymakers in implementation is crucial. Accountability mechanisms such as state standards-based assessments and federal annual improvement goals are likely to continue to get districts' attention. But these instruments on their own will do little to increase opportunities for local policymakers to understand the core ideas about education pressed by the policies connected with accountability. Accountability mechanisms do not address the risk that local policymakers will fail to grasp and thus to implement the instructional reform ideas meant to boost student achievement. Ensuring that districts and teachers interpret reforms as intended remains a vital task. The cognitive perspective on standards implementation used here extends the explanatory power of conventional implementation models by taking into account local interpretations of policy. The implications of this perspective for improving understanding of the movement of instructional reform from capitol to classroom deserve further scrutiny.

\section{About the Author}

James Spillane is Associate Professor of Education and Social Policy, and a Faculty Fellow at the Institute for Policy Research at Northwestern University. For the past 15 years, his research has explored the role of the school district in instructional reform. This work is reported in over 50 papers, book chapters, and policy briefs. For the past six years, Spillane has engaged in an intensive study of school leadership that has undertaken an empirical investigation of the practice of school leadership in urban elementary schools. He is associate editor of Educational Evaluation and Policy Analysis and serves on the editorial board of numerous journals. 


\section{References}

American Association for the Advancement of Science (AAAS). (1989). Science for all Americans. Washington, DC: Author.

Coburn, C. E. (2001). Collective sensemaking about reading: How teachers mediate reading policy in their professional communities. Educational Evaluation and Policy Analysis, 23(2), 145170 .

Educational Evaluation and Policy Analysis (EEPA). (1990). [Special issue devoted to the findings of the California study of elementary mathematics]. Educational Evaluation and Policy Analysis, 12(3).

Finnigan, K., \& Gross, B. (2001, April). Teacher motivation and the Chicago probation policy. Paper presented at the annual meeting of the American Educational Research Association, Seattle, WA.

Firestone, W. A. (1989). Using reform: Conceptualizing district initiative. Educational Evaluation and Policy Analysis, 11(2), 151-164.

Firestone, W. A., Fitz, J., \& Broadfoot, P. (1999). Power, learning, and legitimation: Assessment implementation across levels in the United States and the United Kingdom. American Educational Research Journal, 36(4), 759-793.

Greeno, J. G., Riley M. S., \& Gelman, R. (1984). Conceptual competence and children's counting. Cognitive Psychology, 16, 94-143.

Haug, C. (1999). Local understanding, resources, and policies: Obstacles to standards-based mathematics education reform. Unpublished doctoral dissertation, University of Colorado, Boulder.

Hill, H. (1999). Implementation networks: Nonstate resources for getting policy done. Unpublished doctoral dissertation, University of Michigan, Ann Arbor.

Hill, H. (2001). Policy is not enough: Language and the interpretation of state standards. American Educational Research Journal, 38(2), 289-320.
Koertz, D., Mitchell, K., Barron, S., \& Keith, S. (1996). Perceived effects of the Maryland State Assessment Program (Technical Report No. 406). Los Angeles: University of California, Los Angeles, National Center for Research on Evaluation, Standards, and Student Testing.

Lampert, M. (1986). Knowing, doing, and teaching multiplication. Cognition and Instruction, 3(4), 305-342.

Lane, S., Stone, C., Parke, C., Hansen, M., \& Cerrillo, T. (2000). Consequential evidence for MSPAP from the teacher, principal, and student perspective. Paper presented at the annual meeting of the National Council of Measurement in Education, New Orleans, LA.

Leinhardt, G., \& Smith, D. A. (1985). Expertise in mathematics instruction: Subject matter knowledge. Journal of Educational Psychology, 77(3), 247-271.

Lin, S. (2000). Reform in the making: The implementation of social policy in prison. Princeton, NJ: Princeton University Press.

Mandler, J. (1984). Stories, scripts, and scenes: Aspects of schema theory. Hillsdale, NJ: Erlbaum.

McDonnell, L., \& Choiser, C. (1997). Testing and teaching: Local implementation of new state assessments (Technical Report No. 442). Los Angeles: University of California, Los Angeles, National Center for Research on Evaluation, Standards, and Student Testing.

Romberg, T. (1983). A common curriculum for mathematics. In G. Fenstermacher \& J. Goodlad (Eds.), Individual differences and the common curriculum: Eighty-second yearbook of the National Society for the Study of Education, part 1 (pp. 121-159). Chicago: National Society for the Study of Education.

Spillane, J. P. (1996). School districts matter: Local educational authorities and state instructional policy. Educational Policy, 10(1), 63-87.

Spillane, J. P. (1998). State policy and the nonmonolithic nature of the local school district: Organizational and professional considerations. American Educational Research Journal, 35(1), 3363. 


\section{Policy Briefs}

Spillane, J. P. (2000). Cognition and policy implementation: District policymakers and the reform of mathematics education. Cognition and Instruction, 18(2), 141-179.

Spillane, J. P. (2004). Standards deviation: How schools misunderstand education policy. Cambridge, MA: Harvard University Press.

Stecher, B., Barron, S., Chun, T., \& Ross, K. (2000). The effects of the Washington State education reform on schools and classrooms (Technical Report No. 525). Los Angeles: University of California, Los Angeles, National Center for Research on Evaluation, Standards, and Student Testing.

\section{Nondiscrimination Statement}

The University of Pennsylvania values diversity and seeks talented students, faculty, and staff from diverse backgrounds. The University of Pennsylvania does not discriminate on the basis of race, sex, sexual orientation, religion, color, national or ethnic origin, age, disability, or status as a Vietnam era veteran or disabled veteran in the administration of educational policies, programs, or activities; admissions policies, scholarships, or loan awards; and athletic or University-administered programs or employment. Questions or complaints regarding this policy should be directed to Executive Director, Office of Affirmative Action, 1133 Blockley Hall, Philadelphia, PA 19104-6021 or 215-898-6993 (Voice) or 215-898-7803 (TDD).

\section{About CPRE}

The Consortium for Policy Research in Education (CPRE) studies alternative approaches to education reform in order to determine how state and local policies can promote student learning. Currently, CPRE's work is focusing on accountability policies, efforts to build capacity at various levels within the education system, methods of allocating resources and compensating teachers, instructional improvement, finance, and student and teacher standards. The results of this research are shared with policymakers, educators, and other interested individuals and organizations in order to promote improvements in policy design and implementation.

CPRE unites five of the nation's leading research institutions to improve elementary and secondary education through research on policy, finance, school reform, and school governance. Members of CPRE are the University of Pennsylvania, Harvard University, Stanford University, the University of Michigan, and the University of Wisconsin-Madison.

CPRE Policy Briefs are published by CPRE. To learn more about CPRE research or publications, please call 215-573-0700 or access CPRE publications at www.cpre.org; www.wcer.wisc.edu/cpre/; or www.sii.soe.umich.edu.

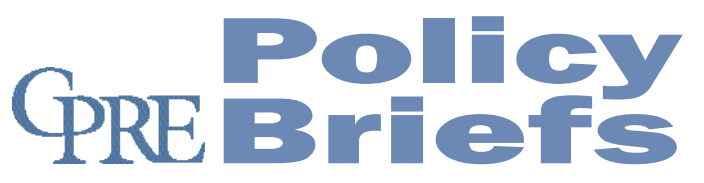

NON PROFIT

U.S. POSTAGE

PAID

PERMIT NO. 2563

PHILADELPHIA, PA

Graduate School of Education

University of Pennsylvania

3440 Market Street, Suite 560

Philadelphia, PA 19104-3325 